\title{
PENGARUH LINGKUNGAN KERJA DAN KARAKTERISTIK INDIVIDU TERHADAP KEPUASAN KERJA KARYAWAN PT. MINAS PAGAI LUMBER
}

\author{
Alex Arianto, Hendrianto Abaharis \\ STIE "KBP" PADANG
}

\begin{abstract}
This study aims to determine the effect of work environment and individual characteristics on job satisfaction PT. Minas Pagai Lumber. The data collection of this research through the spreading of questionnaires to 54 respondents by using slovin formula technique. Based on the result of the research indicate that work environment variable have positive and significant effect to job satisfaction because $t$ value (11,765 with significance value 0,000 smaller than significant level 0,05 and individual characteristic variable have positive and significant effect to job satisfaction because t count (3,343) with a significance value of 0.001 is smaller than the significance level of 0.05 . While the significance value of $F$ test results of 0.000 means significance is smaller than 0.05.It shows that there is a positive and significant influence simultaneously or simultaneously between the work environment and individual characteristics to the work satisfaction of employees of PT Minas Pagai Lumber.
\end{abstract}

Keywords: Work Environment, Individual Characteristics, And Job Satisfaction.

\section{PENDAHULUAN}

Pada era globalisasi seperti saat ini kebutuhan perusahaan akan sumber daya manusia yang handal adalah sebuah hal yang penting. Sumber daya manusia adalah hal yang tidak dapat dipisahkan dari perusahaan, karena kegiatan operasional sebuah perusahaann tentunya tidak terlepas dari sumber daya manusia. Sumber daya manusia adalah harta atau aset yang paling berharga dan paling penting dimiliki oleh organisasi atau perusahaan, karena keberhasilan organisasi ditentukan oleh unsur manusia, Ardana dkk ( 2012)..

Banyak faktor yang mempengaruhi keberhasilan suatu perusahaan. Salah satunya adalah karyawan, karena berkaitan langsung dengan kegiatan organisasi. Dalam hal ini karyawan diharapkan dapat memberikan hasil yang maksimal sehingga tujuan dari perusahaan atau organisasi dapat tercapai. Kepuasan kerja merupakan salah satu faktor bagi karyawan agar dapat bekerja secara maksimal. Dawal dan Taha (2006) menyatakan bahwa kepuasan kerja bagi karyawan merupakan kunci dari sehatnya sebuah perusahaan..

Perusahaan akan kesulitan dalam mencapai tujuannya apabila kondisi dari lingkungan sekitar kurang memadai sehingga semangat kerja karyawan akan rendah dan berpengaruh terhadap kepuasan bekerja di perusahaan tersebut. Menurut Osborn dalam Suwatno dan 
Priansa (2011) kepuasan bekerja merupakan derajat positif atau negatifnya seseorang mengenai berbagai segi tugas-tugas pekerjaan, tempat kerja dan hubungan dengan sesama pekerja. .

Lingkungan kerja merupakan salah satu faktor yang mempengaruhi kepuasan bekerja pegawai. Jika dalam lingkungan sekitar tempat kerja memberikan kesan yang tidak nyaman, pegawai merasa malas untuk bekerja. Hal ini sama seperti apa yang dikatakan oleh Nitisemito dalam Sugiyarti (2012) yakni lingkungan kerja adalah segala sesuatu yang ada di sekitar para pekerja yang dapat mempengaruhi dirinya dalam menjelankan tugas-tugas yang diembannya. Selain lingkungan kerja ada juga faktor yang berpengaruh langsung pada karyawan dan tidak dapat dipisahkan, kepribadian pegawai yang berbeda-beda menjadikan pegawai mempunyai ciri khas tersendiri sehingga membentuk suatu karakteristik individu pada pegawai. Baik buruknya karakteristik individu pegawai tergantung bagaimana mereka mengaplikasikannya. Karakteristik individu yang berbeda-beda ini disebabkan oleh usia, jenis kelamin, jumlah tanggungan, status pernikahan, dan pengalaman kerja pegawai. Robbins (2006) menyatakan bahwa faktor-faktor yang mudah didefinisikan dan tersedia dalam berkas personalia seorang pegawai menampilkan beberapa karakteristik individu, diantaranya ialah:

1. Usia

2. Jenis kelamin

3. Status Perkawinan

4. Jumlah tanggungan

5. Masa jabatan
Karakteristik individu yang berbeda-beda pada setiap individu menciptakan kontribusi kinerja yang berbeda juga pada perusahaan. Pegawai dengan karakteristik yang baik akan menjadikan pegawai tersebut lebih mudah dalam mengerjakan pekerjaannya, sehingga kinerja yang dihasilkan menjadi optimal dan sangat baik pengaruhnya bagi perusahaan. Begitupun sebaliknya, pegawai dengan karakteristik yang buruk akan menghambat perusahaan dalam beroperasi dan berkembang. Berdasarkan hal itulah dapat dipastikan bahwa perusahaan memiliki kriteria tertentu mengenai pegawai yang akan mereka pekerjakan yang sesuai dengan kebutuhan perusahaan.Perusahaan menyadari bahwa pegawai merupakan aset penting sehingga perusahaan perlu memperhatikan keberadaannya dengan memfasilitasi kebutuhan pegawai dalam bekerja.

Penelitian ini bertujuan untuk mengetahui pengaruh Lingkungan kerja dan Karaktersitik terhadap Kepuasan kerja Karyawan PT. Minas Pagai Lumber.

\section{KAJIAN TEORI}

\section{Kepuasan Kerja}

Untuk mengawali pembahasan mengenai kepuasan kerja, perlu ditegaskan bahwa kepuasan kerja mempunyai arti yang beraneka ragam, sehingga timbul berbagai pengertian baik dalam arti konsepnya maupun dalam arti analisisnya. Menurut Rivai (2004), kepuasan kerja pada dasarnya bersifat individual. Setiap individu mempunyai tingkat kepuasan yang berbeda-beda sesuai dengan sistem 
nilai yang berlaku dalam dirinya. Makin tinggi penilaian terhadap kegiatan dirasakan sesuai dengan keinginan individu, maka makin tinggi kepuasannya terhadap kegiatan tersebut. Dengan kata lain, kepuasan merupakan evaluasi yang menggambarkan seseorang atas perasaan sikapnya senang atau tidak senang, puas atau tidak puas dalam bekerja. Hal yang hampir sama juga dikemukakan oleh Kotler (2002) dimana kepuasan kerja diartikan sebagai perasaan senang atau kecewa seseorang yang muncul setelah membandingkan antara persepsi / kerja terhadap kinerja suatu produk dan harapan - harapannya.

Adapun indikator-indikator kepuasan kerja menurut Yuwono dalam Badriyah (2015) meliputi antara lain pekerjaan, gaji, promosi, pengawas, rekan kerja, benefit, Contingent Rewards, Prosedur pelaksanaan.

a. Secara umum, Baron dalam Badriyah (2015) membagi faktorfaktor ini dalam dua kelompok besar, yaitu faktor yang berkaitan dengan individu dan faktor yang berhubungan dengan organisasi. Faktor-faktor tersebut adalah sebagai berikut Faktor-faktor yang berkaitan dengan individu seperti kepribadian, Nilai - nilai yang dimiliki individu, Pengaruh social dan kebudayaan, Minat dan penggunaan keterampilan.

Menurut Arief Subyantoro (2009) menyebutkan bahwa setiap orang mempunyai pandangan, tujuan, kebutuhan dan kemampuan yang berbeda satu sama yang lain. Perbedaan ini terbawa dalam dunia kerja, yang akan menyebabkan kepuasan satu dengan yang lain berbeda ketika bekerja ditempat yang sama. Arief Subyantoro menyebutkan indikator karakteristik individu sebagai berikut: kemampuan, nilai, sikap dan minat.

\section{Lingkungan Kerja}

Definisi lingkungan kerja adalah segala sesuatu yang ada di sekitar para pekerja yang dapat mempengaruhi dirinya dalam menjalankan tugas-tugas yang diembannya (Nitisemito dalam Sugiyarti, 2012). Sama dengan yang dikemukakan oleh Nitisemito dalam Nuraini (2013). Lingkungan kerja adalah segala sesuatu yang ada disekitar karyawan dan dapat mempengaruhi dalam menjalankan tugas yang diembankan kepadanya misalnya dengan adanya air conditioner (AC), penerangan yang memadai dan sebagainya.

Lingkungan kerja di perusahaan terbagi ke dalam dua dimensi yaitu lingkungan kerja fisik dan non-fisik. Menurut Sedarmayanti (2011) menyatakan bahwa dimensi lingkungan kerja fisik terdiri dari beberapa indikator seperti kebisingan, keamanan, penerangan, suhu udara di ruangan, fasilitas, dekorasi di tempat kerja, sedangkan Menurut A.S. Munandar (2010) menyatakan bahwa Dimensi Lingkungan Kerja Non-Fisik terdiri dari beberapa indikator seperti hubungan rekan kerja setingkat, hubungan bawahan, hubungan atasan, Iklim kerja yang dinamis, Budaya perusahaan, kebijakan perusahaan, peraturan-peraturan.

\section{Karakteristik Individu}

Irawan (2012) menjelaskan dalam penelitiannya, karakteristik individu adalah minat, dimana sikap yang membuat seseorang puas akan 
obyek atau ide-ide tertentu. Minat memiliki dampak positif dalam pencapaian kerja. Karakteristik individu harus mendapatkan perhatian serius dari perusahaan.Karakteristik individu akan mendukung perilaku yang kreatif dan pada akhirnya bermuara pada kreatifitas organisasi. Karakteristik individu memiliki komponen sebagai berikut umur, pendidikan, pengalaman kerja, keahlian, jenis kelamin, status perkawinan,

\section{Hipotesis}

H1 : Diduga lingkungan kerja berpengaruh positif terhadap kepuasan kerja.

H2 : Diduga karakteristik individu berpengaruh positif terhadap kepuasan kerja.

\section{METODE PENELITIAN}

Jenis Penelitian

Jenis penelitian dalam penelitian ini adalah penelitian kuantitatif. Menurut Sugiyono (2011) kuantitatif adalah metode penelitian yang berlandaskan pada filsafat positivif yang digunakan untuk meneliti populasi atau sampel tertentu, pengumpulan data menggunakan instrumen penelitian, analisis data bersifat kuantitatif/statistik, dengan tujuan untuk menguji hipotesis yang telah ditetapkan.

\section{Penentuan Sampel}

Dalam menentukan jumlah sampel penelitian mengambil sampel pada karyawan PT.Minas Pagai Lumber berdasarkan rumus Slovin Yaitu sebanyak 54 orang.

\section{Jenis dan Sumber Data}

Jenis data dalam penelitian ini adalah data primer dan sekunder seperti, menyebarkan kuesioner berupa pertanyaan tertulis, dan dokumentasi seperti melihat atau mencatat dokumen-dokumen perusahaan yang berkaitan dengan penelitian.

\section{HASIL PENELITIAN}

\section{Hasil Regresi Berganda}

persamaan regresi linear berganda untuk pengaruh Lingkungan kerja dan karakteristik individu terhadap kepuasan kerja karyawan PT. Minas Pagai Lumber adalah sebagai berikut :

$$
\begin{gathered}
\mathbf{Y}=\mathbf{a}+\mathbf{b}_{\mathbf{1}} \mathbf{X}_{\mathbf{1}}+\mathbf{b}_{\mathbf{2}} \mathbf{X}_{\mathbf{2}}+\mathbf{e} \\
\mathrm{Y}=1.799+0.306 \mathrm{X} 1+0,688 \mathrm{X} 2+\mathrm{e} \\
\text { Maka dapat disimpulkan }
\end{gathered}
$$
bahwa variabel bebas X1 (Lingkungan Kerja) dengan koefisien 0,306 berpengaruh. Kemudian variabel lain yang berpengaruh adalah X2 (Karakteristik individu) dengan koefisien 0,688 dari persamaan tersebut dilihat bahwa variabel Lingkungan Kerja dan Karakteristik individu berpengaruh positif terhadap kepuasan kerja karyawan. Dimana persamaan regresi dua predictor X1 dan X2 bertanda positif, maka dapat diartikan bahwa satu satuan skor Lingkungan Kerja dan Karakteristik individu berpengaruh positif terhadap kepuasan kerja karyawan. Lingkungan Kerja sebesar 0.306 dan Karakteristik individu sebesar 0.688 pada konstanta 1.799 .

\section{Hasil Uji Determinasi}

Model Summary

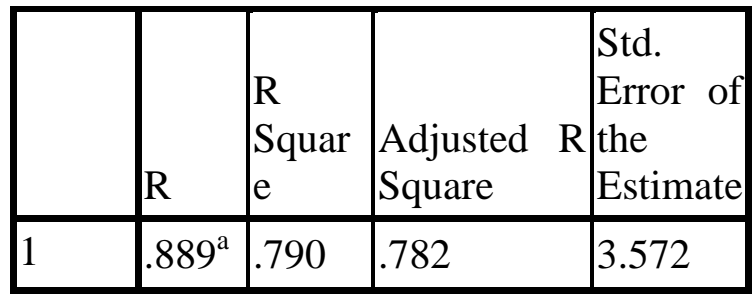

a. Predictors: (Constant), X2, X1 
nilai Adjusted $\mathrm{R}$ Square yang mempunyai nilai 0,79 yang berarti pengaruh $\mathrm{X} 1, \mathrm{X} 2$, perubahan yang terjadi pada lingkungan kerja dan karakteristik individu dapat menjelaskan $79 \%$ terhadap kepuasan kerja karyawan, artinya $21 \%$ dijelaskan oleh variabel lain yang ada di luar model, seperti kompensasi dan promosi.

\section{Hasil Uji Parsial (T)}

Berdasarkan hasil pengolahan data bahwa nilai signifikasi t-hitung $(3,443)$ dan nilai signifikansinya 0,001 . Hal ini berarti signifikasi lebih kecil dari 0,05. Hal ini menunjukkan ada pengaruh yang positif dan signifikan antara lingkungan kerja dan terhadap kepuasan kerja. Jadi hipotesisnya Ho diterima Ha ditolak. Sedangkan signifikan antara kara kerjkteristik individu terhadap kepuasan kerja adalah signifikasi thitung (11.765) dan nilai signifikansinya 0,00 . Hal ini berarti signifikasi lebih kecil dari 0,05. Jadi hipotesisnya Ho diterima Ha ditolak. Hal ini menunjukkan ada pengaruh yang positif dan signifikan antara karakteristik individu dan terhadap kepuasan kerja

\section{Hasil Uji Simultan (F)}

Nilai F hitung sebesar 96.140 yang signifikan $0.000^{b}$ Karena Sig $<0.05$ ini berarti rumusan hipotesis yang menyatakan bahwa Karakteristik Individu dan Lingkungan Kerja berpengaruh secara simultan terhadap Kepuasan Kerja.

\section{KESIMPULAN DAN SARAN kesimpulan}

1. Hasil terdapat pengaruh positif dan signifikan pengaruh variable Karakteristik Individu terhadap variabel Kepuasan Kerja dengan nilai TCR $80.04 \%$

2. Hasil terdapat pengaruh positif dan signifikan pengaruh variabel Lingkungan Kerja terhadap variabel Kepuasan Kerja dengan nilai TCR $78.38 \%$

\section{UCAPAN TERIMAKASIH}

Ucapan terima kasih untuk Bapak Febryandhie Ananda, SE, M.Si selaku Ketua Sekolah Tinggi Ekonomi Keuangan Perbankan dan Pembangunan (STIE'KBP” Padang) beserta Staf pempinan, karyawan dan karyawati di STIE"KBP" Padang bapak Henryanto Abaharis SE, M.Si selaku pembimbing dalam pembantu penulis selama menuntut ilmu yang bermanfaat kepada penulis selama perkuliahan. Teman - teman dan pihak - pihak lain yang membantu penulis dalam menyelesaian skripsi ini yang tidak dapat penulis sebutkan satu persatu namanya.

\section{DAFTAR PUSTAKA}

Ardana, I Komang, Ni Wayan Mujiati dan I Wayan Mudiartha Utama. (2012), Manajemen

Badriyah, M. \& Afifuddin. (2015), Manajemen Sumber Daya Manusia. Bandung : Pustaka Setia.

Dona, E. (2016). Pengaruh Perencanaan, Prosedur Dan Pengawasan dan Komitmen Organisasi Dalam Pelaksanaan Anggaran Terhadap Kinerja Pegawai Dinas Pekerjaan Umum Kota Pariaman. Jurnal Riset Manajemen dan Akuntansi 
(Jurmak), 23-35

Dawal, Siti Zawiah Md and Zahari Taha. 2006. The Effect of Job and Environmental Factors on Job Satisfaction in Automotive Industries. International Journal of Occupational Safety and Ergonomics (JOSE).

Irawan, Andy (2012), "Pengaruh Karakteristik Individu dan Karakteristik Kerja terhadap Organizational Citizenship Behaviors dengan Kepuasan Kerja sebagai Mediator Pada Event Organizer di Surabaya" Fakultas Bisnis dan Manajemen, Universitas Katolik Widya Mandala Surabaya.

John Dewey, (2002), Pengalaman \& Pendidikan, kepel Press, Yogyakarta..

Kotler, Philip. (2000) Manajemen Pemasaran, edisi millennium, jilid 1. Jakarta: PT. Prenhalindo.

Mangkunegara, Anwar Prabu. (2011), Manajemen Sumber Daya Manusia Perusahaan, Bandung : PT. Remaja Rosdakarya.

Marlius, D. RD Putra. (2018). Strategi Pengembangan Sulam Bayang. Jurnal Benefita: Ekonomi Pembangunan Manajemen Bisnis Dan Akuntansi. Volume 3. No. 2. Hal. 204-218. http://doi.org/10.22216/jbe.v3i2. 3494

Nardo, R. Evanita, Syahrizal, S. (2018). Pengaruh Kepemimpinan Transformasional, Dan Lingkungan Kerja Non Fisik Terhadap Perilaku Inovatif. JEBI (Jurnal Ekonomi dan Bisnis Islam) 3 (2), 209-215

Nardo, R. Evanita, Syahrizal, S. (2019). The Effect of
Transformational Leadership and Non Physical Work Environment on Innovative Behavior with Work Motivation as a Mediation For Employees of Tour And Travel Companies In West Sumatera. 2nd Padang International Conference on Education, Economics, Business and Accounting (PICEEBA-2 2018)

Nuraini, T. (2013), Manajemen Sumber Daya Manusia. Pekanbaru: Yayasan Aini Syam.

Putra, RY. Marlius, D. (2019). Pengaruh Pendidikan, Pengalaman Kerja dan Etos Kerja Terhadap Kinerja Pegawai Di KPN Batur. Academic Conference For Management 2.

Rivai, Veithzal. (2004), Manajemen Sumber Daya Manusia Untuk Perusahaan: DariTeori Ke Praktik. Jakarta: PT. Raja Grafindo Persada.

Robbins, Stephen P, (2006), Perilaku Organisasi Edisi Bahasa Indonesia. Trj. Benyamin Molan. Jakarta: PT. Indeks, Kelompok Gramedia.

Sedarmayanti. (2011), Manajemen Sumber Daya Manusia, Reformasi Birokrasi Manajemen Pegawai Negeri Sipil. Bandung : Rafika Aditama.

Susriyanti, S. Nardo, R. (2019). Pengaruh Fungsi Komunikasi Dan Kepuasan Kerja Karyawan Terhadap Pemberian Pelayanan Nasabah PT. BPR LPN Talawi Sakato. Jurnal Administrasi 
Sosial dan Humaniora 3 (2), 97-111.

Sudarmanto, R. Gunawan. Penentuan Besarnya Sampel Penelitian Menggunakan Rumus Cochran. 12 Desember 2011, Januari 2013.

http://staff.unila.ac.id/radengun awan/files/2011/08/Penentuan-

BesarnyaSampel-Menggunakan Rumus-Cochran.pdf.

Sugiyono. (2005). Metode Penelitian

Administrasi. Bandung:

Alfabeta.

Sugiyono. (2014). Metode Penelitian

Kuantitatif, Kualitatif, dan

Kombinasi (Mixed Methods).

Bandung: Alfabeta.

Sugiyarti, Gita. (2012), Pengaruh Lingkungan Kerja, Budaya Organisasi dan Kompensasi terhadap Kepuasan Kerja untuk Meningkatkan Kinerja Pegawai ( Studi pada Fakultas Ekonomi Universitas 17 Agustus 1945 Semarang). Jurnal Ilmiah ,UNTAG Semarang.

Suwatno, dan Donni Juni Priansa, (2011). Manajemen SDM dalam Organisasi Publik dan Bisnis. Bandung: $\mathrm{CV}$. ALFABETA.

Ridho, M., \& Susanti, F. (2019). Pengaruh Stres Kerja Dan Motivasi Kerja Terhadap Kepuasan Kerja Pada Karyawan Bank Mandiri Syariah Cabang Padang. https://doi.org/10.31227/osf.io/ pa2cg

Lubis, A. Y. O., \& Susanti, F. (2019). Pengaruh Gaya Kepemimpinan Dan Kompensasi Terhadap Prestasi Kerja Karyawan (Studi pada PT Japfa Comfeed
Indonesia (JCI) Tbk Devisi Fam 1. https://doi.org/10.31227/osf.io/ 7tbrg

Yudistira, D. S., \& Susanti, F. (2019). Pengaruh Motivasi Kerja Dan Budaya Kerja Terhadap Kinerja Karyawan Dinas Pemberdayaan Masyarakat Dan Desa, Pengendalian Penduduk Dan Keluarga Berencana Kabupaten Pesisir Selatan. https://doi.org/10.31227/osf.io/j $\mathrm{k} 54 \mathrm{~m}$ 